\title{
e.Learning, una necesidad inaplazable
}

\author{
Guillermo Vázquez*, Carmen Blanco** \\ *Director de I+D, Fundación IAVANTE **Directora Gerente de la Fundación IAVANTE
}

Esta monografía de Educación Médica centrada en e.Learning, intenta dar a sus lectores una visión global y actualizada de sus diferentes facetas. Profesores, tutores o simplemente cualquier persona del ámbito sanitario interesada en la docencia, encontrará en esta monografía los conocimientos necesarios para adentrarse en el e.Learning y responder a las preguntas y dudas que le vayan surgiendo. La monografía ha sido escrito por un panel de especialistas pertenecientes a centros y universidades de prestigio Internacional, como son la "Universitat Oberta de Catalunya", La Universidad de Sevilla, La Universidad Autónoma de Barcelona, La Fundacion IAVANTE de la Junta de Andalucía ${ }^{a}$, la Universidad "Tecnológico de Monterrey" de Méjico, o de la World Health Organization.

A nuestro entorno, hasta ahora definido por dos espacios, uno personal y otro social y cultural, le hemos añadido un nuevo espacio, el virtual. Este nuevo espacio se sustenta en las tecnologías de la Información y Comunicación (TICs) y está cada vez mas presente en nuestras actividades diarias (compras, bancos, correo, música etc.), a la vez que va haciendo realidad nuevos horizontes como es la Sociedad del Conocimiento de inicios del Siglo XXI. Esta nueva sociedad, solo se consolidará si las TICs aplicadas a la formación a distancia, es decir el e.Learning, se generaliza y se facilita su accesibilidad.

El lector rápidamente percibirá que el e.Learning constituye una opción estratégica básica para las instituciones universitarias (enfermería y medicina), para otras instituciones como las sanitarias que necesitan el reciclaje permanente de sus profesionales. El e.Learning transforma el papel tradicional de los profesores, requiere una nueva organización y nuevas aproximaciones metodológicas y pedagógicas. Sin embargo este cambio se enfrenta con diferentes retos que deben de visualizarse claramente, uno es el coste de su implantación, otro la ausencia de equipos en número suficiente para favorecer su accesibili- dad, junto al bajo nivel de digitalización de una gran mayoría de profesores. También y no menos importantes que las anteriores son las costumbres basadas en la lección magistral, en el contacto directo, y la carencia de tiempo por parte de los profesores para dedicarse con garantías de éxito al diseño de contenidos y seguimiento de las acciones educativas. También es necesaria la aceptación social del e.Learning, siendo necesarias alianzas entre profesores, alumnos y ciudadanos en general, como única manera de asegurar la gobernabilidad del proyecto. Por tanto la necesidad de un fuerte liderzazo para impulsar e implantar el cambio del e.Learning es necesario.

Actualmente, la objetividad científica en cualquier actividad relacionada con la medicina, ha originado el concepto de Medicina y Enfermería Basada en la Evidencia, y de la mano de ella el concepto de Educación Médica Basada en la Evidencia. Este concepto quiere decir que la formacion y entrenamiento de los profesionales debe de basarse en estudios bien diseñados y con objetivos claramente definidos. El e.Learning debe, por tanto ser objeto de estudios y análisis en sus diferentes aspectos. El lector encontrará en la monografía las preguntas mas frecuentes que debe de responder la investigación educativa basada en la formacion online.

Otro aspecto importante de la monografía es su aproximación sencilla a los temas tecnológicos. La simplicidad en su exposición, permite a los que no somos expertos en estos tópicos darnos cuenta de la infraestructura que subyace detrás del e.Learning. Por un lado los equipos tecnológicos que dan soporte al e.Learning, y que van más allá del computar personal. Por otro lado el conjunto de plataformas de software, que superpuestas unas sobre otras permiten desde la gestión administrativa hasta el diseño de los cursos, la evaluación de los mismos y el empleo de diversos recursos multimedia y herramientas de comunicación y colaborativas. Paralelamente el lector identificará el significado de plataformas propietarias y 
abiertas, sus ventajas e inconvenientes. Este conocimiento le ayudará en sus decisiones estratégicas.

Diversos ejemplos de formacion e.Learning pura, o la combinación de diferentes metodologías, permiten visualizar el amplio abanico de posibilidades del e.Learning. Los profesionales de la sanidad, utilizaban hasta ahora el currículo vitae, como única herramienta para objetivar su formacion y conocimiento; sin embargo nuevos conceptos como Carrera Profesional, Desarrollo Profesional, o recertificación, le obligan a ampliar el concepto de currículum vitae con aquellas evidencias que permitan evidenciar su práctica diaria objetivamente, y detectar aquellos puntos que deben de reforzarse. El Portfolio constituye la herramienta que permite recoger este conjunto de dimensiones curriculares en tiempo real; el ePortfolio es el equivalente electrónico. El ePorfolio se está recomendando como una las herramientas que deben de acompañar el nuevo espacio virtual del e.Learning.

Finamente, los costes globales, es decir la compra de equipos, el diseño y actualización de los contenidos de los cursos de calidad, su mantenimiento, las personas a cargo de las plataformas y de la preparación del material docentes, requieren un claro análisis de los mismos. En cualquier caso y especialmente en relación con los cursos, solo un mercado de contenidos docentes, al igual que existen otros mercados virtuales puede asegurar el despliegue de todas las potencialidades del e.Learning. Este mercado requiere la interoperabilidad de sus plataformas, la reutilización de contenidos y la cobertura de aspectos legales como son los derechos de autor.

Esta breve exposición sobre e.Learning, asegura al lector el interés de los artículos que encontrará en ella. 